\title{
Dosimetric Comparison of Different Radiotherapy Techniques to Determine the Absorbed Fetal Dose in Pregnant Patients with Left-Sided Breast Cancer
}

\author{
Osman Vefa Gul *, Gokcen Inan, Hamit Basaran \\ Selcuk University, Faculty of Medicine, Department of Radiation Oncology, Konya, Turkey
}

\begin{tabular}{l} 
ART ICLE INFO \\
\hline Article history: \\
Received: $26^{\text {th }}$ Mar. 2021 \\
Accepted: $2^{\text {nd }}$ June 2021 \\
\hline
\end{tabular}

Keywords:

Pregnancy;

Breast Cancer;

Radiation Therapy;

Fetal Dose.

\begin{abstract}
This study aimed to measure the dose exposed by the fetus during three-dimensional conformal radiotherapy (3D-CRT) and intensity-modulated radiotherapy (IMRT) treatment techniques in pregnant patients who had to undergo radiotherapy due to breast cancer with thermoluminescence dosimetry (TLD) and compare these measurements with treatment planning system (TPS). $2.5 \mathrm{~mm}$ - thick computed tomography (CT) images of Alderson Rando phantom device were taken for measurements. Heart, ipsilateral lung, contralateral lung and contralateral breast were defined as critical organs at risk (OARs) and planned tumor volume (PTV) as target volume. In TPS (Eclipse, version 15.1), using 3D-CRT and IMRT treatment methods, the criterion that $95 \%$ of the PTV volume should receive more than $95 \%$ of the predicted dose was taken into consideration. OAR has been preserved as much as possible in the used techniques. In order to compare the TPS and TLD readings in PTV, 60 TLDs were placed in the target volume in the Rando phantom. Twenty-four TLDs were placed in the 30th and 31st sections of the phantom, which is likely to be in the volumetric size of the first trimester of pregnancy which is also located $25.84 \mathrm{~cm}$ from the lower limit of the PTV. Six MV were used in seven different treatment techniques and the measurements were repeated 5 times for each technique and averaged. The differences between the average TPS and TLD readings for PTV were $1.34 \%, 0.86 \%, 1.04 \%, 0.64 \%, 0.48 \%, 0.84 \%$ and $0.73 \%$ for $3 D-C R T$, 5 MSS-IMRT, 5 SW-IMRT, 7 MSS-IMRT, 7 SW-IMRT, 9 MSS-IMRT and 9 SW-IMRT, respectively. Fetal doses for all treatment techniques in TPS were found as $0.00 \mathrm{cGy}$. However, in TLD measurements fetal doses were found as, $3.36 \pm 0.19$ cGy, $9.32 \pm 0.91$ cGy 10.29 $\pm 1.19 \mathrm{cGy}, 12.35 \pm 1.42 \mathrm{cGy}, 12.99 \pm 1.46 \mathrm{cGy}, 13.18 \pm 1.53 \mathrm{cGy}$ and $16.10 \pm 2.04 \mathrm{cGy}$ for 3D-CRT, 5 MSS-IMRT, 5 SW-IMRT, 7 MSS-IMRT, 7 SW-IMRT, 9 MSS-IMRT and $9 \mathrm{SW}$-IMRT, respectively. In 3D-CRT treatment technique the fetus received the lowest dose. In addition, for plans made using the IMRT method, it is seen that the MSS-IMRT technique provides better fetal protection compared to the SW-IMRT technique. The 3D-CRT should be the first priority for a pregnant patient who has to undergo left breast RT, but if the desired dose-volume histogram (DVH) cannot be obtained with 3D-CRT, 5 MSS-IMRT technique may be preferred.
\end{abstract}

\section{INTRODUCTION}

Diagnosis of cancer sometimes becomes evident after pregnancy or unnoticed pregnancy. Recently, with the increasing reproductive age, the risk of cancer during pregnancy has also increased [1, 2]. Breast cancer is rarely diagnosed during pregnancy, with an incidence of approximately $1 / 3000$ [3]. Although radiotherapy (RT) is one of the most important approaches in the treatment of breast cancer, it is not preferred during pregnancy, but sometimes RT is inevitable [1]. The fetus should be protected as much as possible during RT to be applied in pregnancy or treatment phase during pregnancy. The radiation dose to which the fetus is exposed and the effects that may occur may also vary according to the stage of pregnancy. According to the generally accepted opinion stated by the International Commission on Radiological Protection (ICRP), there is no need for termination of pregnancy in case fetus is exposed to doses below 10 cGy [4]. Between the 2nd and the 16th gestational weeks, organ formation takes place intensively. At this stage, exposure to doses of $10 \mathrm{cGy}$ or higher increases the risk of developmental disorders in organs. For this reason, it is important to know the dose 
to which the fetus is exposed. The fetus can be considered as a peripheral organ at risk for RT applied for breast cancer. Three-dimensional conformal radiotherapy (3D-CRT) and intensity modulated radiotherapy (IMRT) are widely used in left breast RT. IMRT technique can produce better solutions in complex geometric structures than 3D-CRT [5]. Intensity modulated radiotherapy is a treatment technique where there is no gantry movements during dose adjustment. The algorithm determines the weight of the beamlets forming the beam according to the physical parameters of the multileaf collimator (MLC) leaves, such as width, speed of movement. The dose calculation algorithm then calculates the dose distribution. Multiple static segments (MSS) and sliding window (SW) IMRT techniques are used [6]. In the MSS-IMRT technique, dosing is achieved with many fields, each with a homogeneous flux. During irradiation, MLCs do not move dynamically. MLCs take their positions in subfields defined in the planning system and then the device irradiates. The sum of subfields forms a main field where the desired dose setting is achieved. The SW-IMRT technique, is a treatment technique where MLCs are in dynamic motion during irradiation and provide dose adjustments, but the gantry does not move. Each leaf can move at different speeds and provide variability of the spacing between leaves. Movement of MLC leaves is realized according to the time-dependent integral of subfields. The treatment planning system (TPS) (Eclipse, version 15.1; Varian Medical System Inc, Palo Alto, CA, USA) accurately calculates doses within target areas, but the accuracy of out-of-field dose calculations decrease as moved away from the target area $[7,8]$. In cases where dose cannot be calculated using TPS, the best method is to measure the dose with thermoluminescence dosimetry (TLD) using an anthropomorphic Rando phantom.

In this study, it was aimed to measure the radiation absorbed in the fetus (and also in the uterus) with TLD during 3D-CRT and IMRT treatment techniques in pregnant patients who received radiotherapy due to breast cancer and to compare these measurements with those of TPS.

\section{MATERIALS AND METHODS}

The breast area, where high energy radiation is used more often, was selected as the target treatment area. After special treatment planning for 3D-CRT, MSS-IMRT (5, 7 and 9-field) and SW-IMRT (5, 7 and 9-field) techniques in Varian DHX (Varian Medical Systems, Palo Alto, California, USA) TLD-100 dosimeters were placed in the places in the determined volume in the Rando phantom and irradiation was performed. Then, in vivo dose measurements obtained for each technique were compared with those of the TPS.

\section{1. Alderson rando phantom}

The Alderson brand female Rando phantom is manufactured in accordance with the human shaped (anthropomorphic) phantom tissue features, which have real human dimensions and density inhomogenities of organs. Tissue density is $0.975 \mathrm{gr} / \mathrm{cm}^{3}$ and the density of the lungs is $0.25-0.3 \mathrm{gr} / \mathrm{cm}^{3}$. Bone density in the structure of the Rando phantom is equal to that of human bone density. The phantom consists of 35 sections with a thickness of $2.5 \mathrm{~cm}$. The breast volume of the phantom is approximately $800 \mathrm{ml}$. The phantom was prepared and fixed with a special vacuum mattress for the patient as if it were a real breast cancer patient Fig.1.

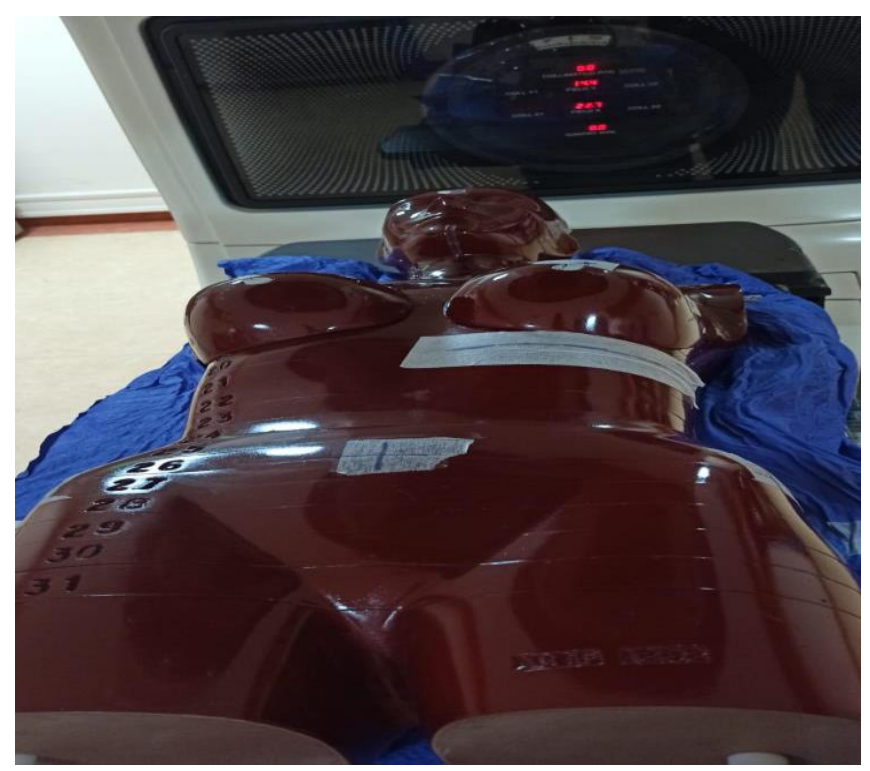

Fig. (1): Preparation of the phantom.

\section{2. Computed tomography and contouring}

The Rando phantom was laid on its back on the computed tomography (CT)(Toshiba Aquilion S4) table and the $2.5 \mathrm{~mm}$ thick CT images were taken by placing markers so that the left breast area is the treatment area. The CT images obtained were transferred to TPS via DICOM network. Clinical tumor volume (CTV) was defined over CT images according to The Radiation Therapy Oncology Group (RTOG) contouring atlas and planned tumor volume (PTV) was created by leaving a 3 $\mathrm{mm}$ margin. PTV was pulled in $2 \mathrm{~mm}$ from the skin and given its final form. At risk organs (OARs) close to the target volume (left and right lung, heart, contralateral breast) and the fetus representing the first trimester was contoured in the pelvis. All contouring procedures were described by a single radiation oncologist. 


\section{3. Treatment planning}

In our study, "Anisotropic Analytical Algorithm, AAA" algorithm was used for dose calculations of 3DCRT, MSS-IMRT (5, 7 and 9-field) and SW-IMRT (5, 7 and 9-field) plans created using Eclipse V.15.1 planning system. Two mutual tangential field techniques were used for 3D-CRT. For tangential treatment angles $305^{\circ}$ and $132^{\circ}$ gantry angles were determined. The same gantry angles were used for the plans created with the MSS-IMRT and SW-IMRT techniques. For 5 field IMRT $310^{\circ}, 350^{\circ}, 20^{\circ}, 60^{\circ}$ and $115^{\circ}$; for 7 field IMRT305 $, 335^{\circ}, 5^{\circ}, 35^{\circ}, 65^{\circ}, 95^{\circ}$ and $130^{\circ}$ and for 9 field-IMRT $300^{\circ}, 320^{\circ}, 345^{\circ}, 10^{\circ}, 35^{\circ}, 60^{\circ}, 85^{\circ}, 110^{\circ}$ and $135^{\circ}$ gantry angles were chosen. The target volume assumed to have undergone breast conserving surgery was irradiated with $6 \mathrm{MV}$ photon energy to receive 50 Gy ( 2 Gy x 25 fr). For all plans, the criterion that the maximum dose in PTV should not exceed $107 \%$ and that 95\% of the volume of PTV should receive more than $95 \%$ of the prescribed dose were taken into consideration. Target dose limits (TDLs) for organs at risk were determined as follows: for heart mean dose $\left(\mathrm{D}_{\text {mean }}\right) 5 \mathrm{~Gy}, \mathrm{~V}_{10}$ Gy and field dose -volume $\left(\mathrm{V}_{10}\right)$ $<35 \%$; for ipsilateral lung $\mathrm{V}_{20}<20 \%, \mathrm{~V}_{10}<40 \%$ and $\mathrm{V}_{5}<55 \%$; for contralateral breast $\mathrm{D}_{\text {mean }}<2 \mathrm{~Gy}$, and maximum dose $\left(D_{\text {mean }}\right) V_{5}<20 \%$. The values of all treatment plan techniques were obtained from the dosevolume histogram (DVH). The lineer accelerator specifications are summarized in Table 1.

\section{4. Measurements}

TLD-100 dosimeters made by doping natural lithium fluoride (LiF) crystals in the form of chips of $3.2 \mathrm{~mm} \times 3.2 \mathrm{~mm} \times 0.9 \mathrm{~mm}$ with $\mathrm{Mg}$ and $\mathrm{Ti}$ were used. Calibration of TLDs was made by using Varian DHX linear accelerator device and bolus, each TLD was irradiated to receive $1 \mathrm{~Gy}$ at $10 \mathrm{~cm} \times 10$ area, from SSD (source - skin distance) of $100 \mathrm{~cm}$ and $1.5 \mathrm{~cm}$ depth from the surface. For each treatment technique, TLDs were removed after irradiation and measurements were made. Before starting the reading process of TLDs, preheating process was carried out in the oven at $100{ }^{\circ} \mathrm{C}$ for 10 minutes in order to remove the luminescence signals caused by unstable traps. In order to compare the TPS and TLD readings in PTV, 60 TLDs were placed in the target volume in the Rando phantom. Twenty-four TLDs were placed in the 30th and 31st sections of the phantom, which was located $25.84 \mathrm{~cm}$ from the lower border of the PTV and likely to be in the volumetric size of the first trimester pregnancy. The phantom was presumed to be local breast cancer and was treated separately with 3D-CRT and IMRT techniques. All TLD measurements were repeated 5 times.

\section{5. Dose evaluation}

Before CT, markers that would not create artifacts were placed in each localization in the Rando phantom and these localizations were contoured separately in TPS. By using 3D-CRT, 5-field IMRT, 7-field IMRT and 9-field IMRT techniques, the point doses to be directed at the localizations were determined in the plans so as to ensure that PTV received a dose of $50 \mathrm{~Gy}$. For each technique TLDs were placed in predetermined localizations in the Rando phantom. In the study, instead of irradiating the phantom for 25 days, a total of 5 irradiations were performed with a dose of $2 \mathrm{~Gy}$ for each irradiation and the doses delivered to the determined localizations during a single treatment session were specified by taking the average of these doses. Then, the results were calculated by multiplying by 25 to determine the doses received by these regions as a result of 25 fractions. The absorbed doses at the specified localizations were read and compared with the dose values obtained from TPS.

\section{6. Statistical analysis}

All data were recorded and analyzed in Statistical Package for Social Sciences (SPSS) software (version 25.1, IBM). Paired-samples t-test was used to evaluate the relationship between TPS and TLD dose measurements for different treatment plans. $\mathrm{p}<0.005$ was considered statistically significant.

Table (1): Lineer accelarator specifications

\begin{tabular}{ccccccc}
\hline $\begin{array}{c}\text { Power } \\
\text { Source }\end{array}$ & $\begin{array}{c}\text { Photon } \\
\text { energies }\end{array}$ & $\begin{array}{c}\text { Elektron } \\
\text { energies }\end{array}$ & \multicolumn{1}{c}{$\begin{array}{c}\text { Multi-Leaf } \\
\text { Collimatör(MLC) }\end{array}$} & $\begin{array}{c}\text { Treatment } \\
\text { delivery }\end{array}$ & $\begin{array}{c}\text { Portal Image } \\
\text { (EPID) }\end{array}$ & $\begin{array}{c}\text { Dose Rate } \\
\text { (MU / min) }\end{array}$ \\
\hline Klystron & 6,18 & $4,6,9,12,15,18$ & $\begin{array}{l}80 \text { MLC Field Size } \\
(40 \times 40)\end{array}$ & $\begin{array}{l}\text { 3 DCRT } \\
\text { IMRT }\end{array}$ & aS500 & $\begin{array}{l}100,200,300, \\
400,500,600\end{array}$ \\
\hline
\end{tabular}




\section{RESULTS}

\section{1. Dose-volume histogram (DVH) evaluation}

PTV, homogeneity index (HI), conformity index (CI), total MU and active irradiation times for seven different treatment techniques created in Eclipse TPS are shown in Table 2. Accordingly mean PTV doses were 5062.10 cGy, 5058.91 cGy, 5088.83 cGy, 5099.65 cGy, $5096.91 \mathrm{cGy}, 5083.70 \mathrm{cGy}$ and $5090.42 \mathrm{cGy}$ for 3D-CRT, 5 MSS-IMRT, 5 SW-IMRT, 7 MSS-IMRT, 7 SW-IMRT, 9 MSS-IMRT and 9 SW-IMRT, respectively. The criterion that $95 \%$ of the volume of PTV should receive more than $95 \%$ of the prescribed dose was fulfilled for all planning techniques. The dose distribution of seven plans in the isocenter field analyzed in this study is shown in Fig. 2. As shown in Table 2, delivery times were $0.91,3.81,4.18,3.98,4.65,4.74$, and 5.00 minutes for 3D-CRT, 5 MSS-IMRT, 5 SW-IMRT, 7 MSS-IMRT, 7 SW-IMRT, 9 MSS-IMRT and 9 SW-IMRT, respectively. Accordingly, the shortest delivery time was seen in the 3D-CRT technique. In addition, it was found that delivery time in MSS-IMRT technique is shorter relative to the SW-IMRT technique. Statistical dosimetric comparisons for OARs are given in Table 3. Accordingly, the $\mathrm{V}_{20}$ values of the ipsilateral lung were detected to be $19.00 \%, 16.89 \%, 17.09 \%$, $15.425,15.65 \%, 14.20 \%$ and $14.87 \%$. for 3D-CRT, 5 MSS-IMRT, 5 SW-IMRT, 7 MSS-IMRT, 7 SW-IMRT, 9 MSS-IMRT and 9 SW-IMRT techniques, respectively. The 9 MSS-IMRT technique provided the best protection for $\mathrm{V}_{20}$ of the ipsilateral lung. $\mathrm{D}_{\text {mean }}$ values of the heart for 3D-CRT, 5 MSS-IMRT, 5 SW-IMRT, 7 MSSIMRT, 7 SW-IMRT, 9 MSS-IMRT and 9 SW-IMRT techniques were $198.08 \mathrm{cGy}, 449.12 \mathrm{cGy}, 498.91 \mathrm{cGy}$ $460.73 \mathrm{cGy}, 487.61 \mathrm{cGy}, 405.24 \mathrm{cGy}$ and $447.74 \mathrm{cGy}$, respectively. The best protection for the heart was provided in the 3D-CRT technique. In all planning techniques MSS-IMRT technique provided better protection than SW-IMRT technique for OARs. In TPS, fetal doses for all treatment techniques were found as $0.00 \mathrm{cGy}$.

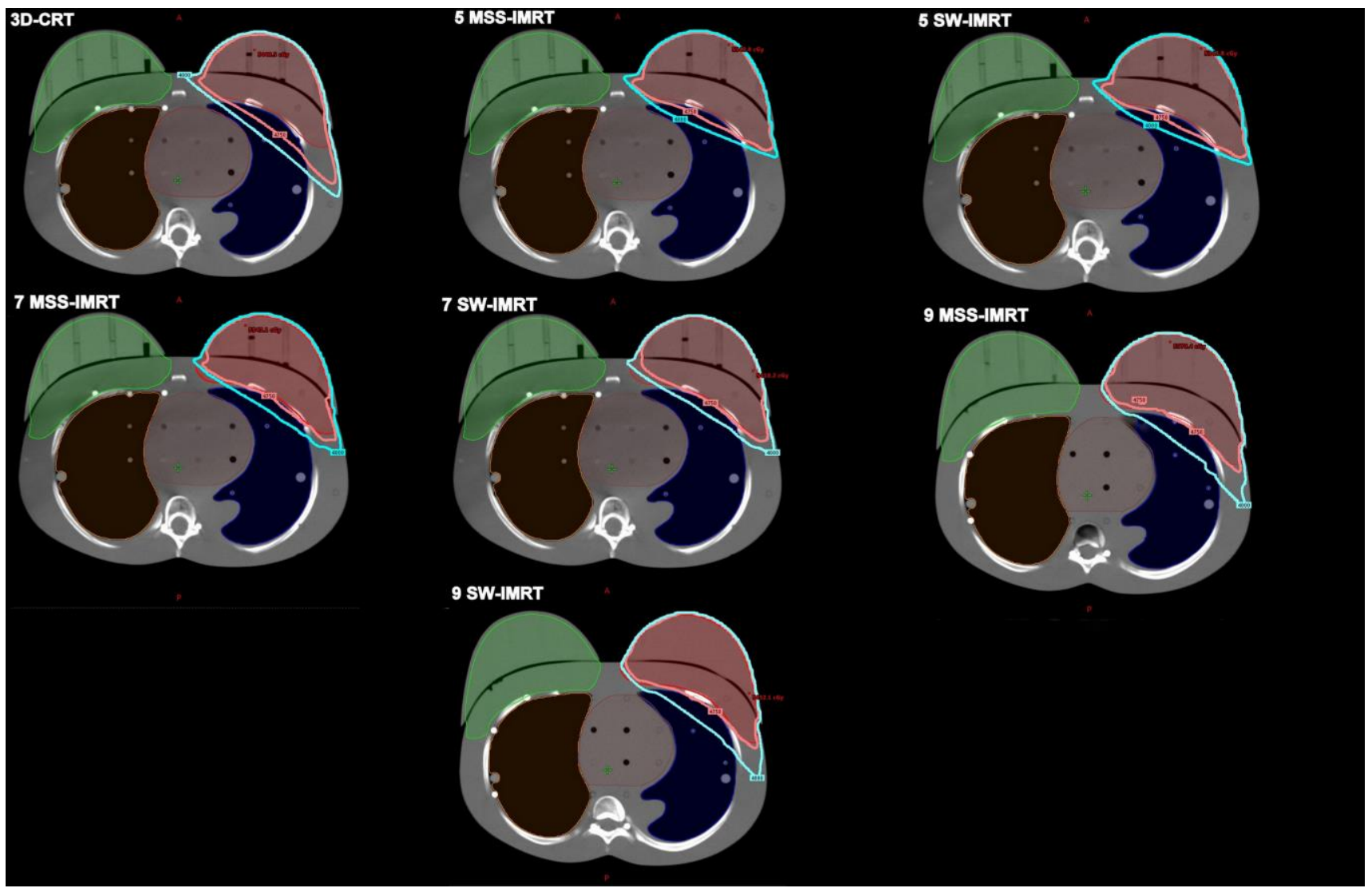

Fig. (2): The dose distribution of seven plans. Red: PTV, green: contralateral breast, heart: Brown, ipsilateral lung: blue, contralateral lung: orange, dose distribution of $4000 \mathrm{cGy}$ : cyan, dose distribution of $4750 \mathrm{cGy}$ : pink 
Table (2): Dose statistic comparison for planning target volume

\begin{tabular}{|c|c|c|c|c|c|c|c|}
\hline Parameters & 3D-CRT & $\begin{array}{c}5 \text { Field } \\
\text { MSS- IMRT }\end{array}$ & $\begin{array}{c}5 \text { Field } \\
\text { SW- IMRT }\end{array}$ & $\begin{array}{c}7 \text { Field } \\
\text { MSS- IMRT }\end{array}$ & $\begin{array}{c}7 \text { Field } \\
\text { SW- IMRT }\end{array}$ & $\begin{array}{c}9 \text { Field } \\
\text { MSS- IMRT }\end{array}$ & $\begin{array}{c}9 \text { Field } \\
\text { SW- IMRT }\end{array}$ \\
\hline PTV D 98 (cGy) & 4437.46 & 4680.15 & 4684.39 & 4541.65 & 4551.48 & 4430.65 & 4594.48 \\
\hline PTV D 95 (cGy) & 4755.91 & 4785.81 & 4818.65 & 4759.81 & 4801.65 & 4780.81 & 4820.65 \\
\hline PTV D 90 (cGy) & 4800.29 & 4988.71 & 4905.91 & 4841.73 & 4918.83 & 4844.46 & 4940.65 \\
\hline PTV D 50 (cGy) & 5107.67 & 5012.73 & 5017.24 & 5093.73 & 5102.24 & 5078.73 & 5118.24 \\
\hline $\mathrm{PTV} \mathrm{D}_{2}$ (cGy) & 5320.20 & 5209.19 & 5206.10 & 5330.19 & 5310.10 & 5345.19 & 5338.10 \\
\hline PTV D mean $_{\text {(cGy) }}$ & 5062.10 & 5058.91 & 5088.83 & 5099.65 & 5096.91 & 5083.70 & 5090.42 \\
\hline $\mathrm{CI}$ & 0.81 & 0.54 & 0.63 & 0.74 & 0.84 & 0.73 & 0.89 \\
\hline $\mathrm{HI}$ & 0.17 & 0.11 & 0.10 & 0.16 & 0.15 & 0.18 & 0.15 \\
\hline MU & 228 & 896 & 1047 & 995 & 1163 & 1184 & 1400 \\
\hline Delivery time & 0.91 & 3.81 & 4.18 & 3.98 & 4.65 & 4.74 & 5.00 \\
\hline
\end{tabular}

Dmean: Mean dose, CI: Conformity Index, HI: Homogeneity Index, MU: Monitor Unit, 3D-CRT: Three-dimensional conformal radiotherapy, MSS-IMRT: Multiple static segments-intensity modulated radiotherapy, SW-IMRT: Sliding window- intensity modulated radiotherapy

Table (3) Dose statistics comparison for organs at risk

\begin{tabular}{llccccccc}
\hline Parameters & & $\begin{array}{c}\text { 3D- } \\
\text { CRT }\end{array}$ & $\begin{array}{c}\text { 5 Field } \\
\text { MSS- IMRT }\end{array}$ & $\begin{array}{c}\text { 5 Field } \\
\text { SW- IMRT }\end{array}$ & $\begin{array}{c}\text { 7 Field } \\
\text { MSS- IMRT }\end{array}$ & $\begin{array}{c}\text { 7 Field } \\
\text { SW- IMRT }\end{array}$ & $\begin{array}{c}\text { 9 Field } \\
\text { MSS- IMRT }\end{array}$ & $\begin{array}{c}\text { 9 Field } \\
\text { SW- IMRT }\end{array}$ \\
\hline Ipsilateral lung & $\mathrm{V}_{5}(\%)$ & 25.27 & 49.60 & 51.28 & 53.11 & 53.29 & 47.23 & 48.64 \\
& $\mathrm{~V}_{10}(\%)$ & 21.40 & 28.15 & 29.97 & 29.33 & 29.87 & 27.53 & 29.03 \\
& $\mathrm{~V}_{20}(\%)$ & 19.00 & 16.89 & 17.09 & 15.42 & 15.65 & 14.20 & 14.87 \\
\multirow{2}{*}{$\begin{array}{l}\text { Heart } \\
\text { Contralateral lung }\end{array}$} & $\mathrm{D}_{\text {mean }}(\mathrm{cGy})$ & 198.08 & 449.12 & 498.91 & 460.73 & 487.61 & 405.24 & 447.74 \\
& $\mathrm{~V}_{10}(\%)$ & 0.95 & 7.52 & 7.78 & 9.90 & 10.15 & 4.51 & 4.94 \\
& $\mathrm{~V}_{5}(\%)$ & 4.56 & 9.54 & 9.80 & 11.15 & 12.83 & 3.78 & 3.70 \\
$\begin{array}{l}\text { Contralateral } \\
\text { breast }\end{array}$ & $\mathrm{D}_{\text {mean }}(\mathrm{cGy})$ & 140.15 & 165.91 & 188.91 & 190.73 & 200.73 & 171.61 & 187.35 \\
& $\mathrm{D}_{\text {max }}(\mathrm{cGy})$ & 816.21 & 881.45 & 875.95 & 923.45 & 955.79 & 986.73 & 989.15
\end{tabular}

Dmean: Mean dose, Dmax: Maximum dose, 3D-CRT: Three-dimensional conformal radiotherapy, MSS-IMRT: Multiple static segments-intensity modulated radiotherapy, SW-IMRT: Sliding window- intensity modulated radiotherapy

\section{2. TLD Measurements}

Average reading values of TLDs irradiated in Varian DHX treatment device and fetal doses in Eclipse 15.1 TPS for seven different treatment techniques are given in Table 4 . The differences between the average TPS and TLD readings for PTV were $1.34 \%, 0.86 \%$, $1.04 \%, 0.64 \%, 0.48 \%, 0.84 \%$ and $0.73 \%$ for 3D-CRT, 5 MSS-IMRT, 5 SW-IMRT, 7 MSS-IMRT, 7 SW-IMRT, 9 MSS-IMRT and 9 SW-IMRT, respectively, Within the target volume, TPS and TLD reading values were below $2 \%$ for all treatment techniques. The dose delivered to fetus which is $37.5 \mathrm{~cm}$ from the isocenter and $25 \mathrm{~cm}$ from the lower limit of PTV, was calculated by TPS as $0 \mathrm{cGy}$ in all treatment techniques. However, TLD measurements of average fetal doses were $3.36 \pm 0.19$ cGy, $9.32 \pm 0.91$ cGy $10.29 \pm 1.19$ cGy, $12.35 \pm 1.42$ cGy, $12.99 \pm 1.46 \mathrm{cGy}, 13.18 \pm 1.53 \mathrm{cGy}$ and $16.10 \pm$ 2.04 cGy for 3D-CRT, 5 MSS-IMRT, 5 SW-IMRT, 7 MSS-IMRT, 7 SW-IMRT, 9 MSS-IMRT and 9 SWIMRT, respectively. In 3D-CRT treatment technique fetus received the lowest dose. In addition, for plans made using the IMRT method, it was seen that the MSSIMRT technique provided better fetal protection compared to the SW-IMRT technique. As the number of fields for MSS-IMRT and SW-IMRT techniques increased, the fetal dose increased. 
Table (4): Dose values measured with TLDs irradiated in Varian DHX treatment device and calculated with Eclipse TPS.

\begin{tabular}{|c|c|c|c|c|}
\hline \multirow{2}{*}{ Technique } & & \multicolumn{2}{|c|}{ PTV Dmean (cGy) } & \multirow{2}{*}{ Fetus Dmean (cGy) } \\
\hline & & Dmean (cGy) & Difference $(\%)$ & \\
\hline \multirow{3}{*}{ 3D-CRT } & TPS & $5062.10 \pm 50.39$ & \multirow{3}{*}{1.34} & $0.00 \pm 0.00$ \\
\hline & TLD & $5130.91 \pm 65.88$ & & $3.36 \pm 0.19$ \\
\hline & $\mathbf{p}$ & 0.008 & & $0.000 *$ \\
\hline \multirow{3}{*}{$\begin{array}{c}5 \text { Field } \\
\text { MSS- IMRT }\end{array}$} & TPS & $5058.91 \pm 33.61$ & \multirow{3}{*}{0.86} & $0.00 \pm 0.00$ \\
\hline & TLD & $5103.19 \pm 52.83$ & & $9.32 \pm 0.91$ \\
\hline & $\mathbf{p}$ & $0.001 *$ & & $0.000 *$ \\
\hline \multirow{3}{*}{$\begin{array}{c}5 \text { Field } \\
\text { SW- IMRT }\end{array}$} & TPS & $5088.83 \pm 14.47$ & \multirow{3}{*}{1.04} & $0.00 \pm 0.00$ \\
\hline & TLD & $5142.50 \pm 69.66$ & & $10.29 \pm 1.19$ \\
\hline & $\mathbf{p}$ & $0.002 *$ & & $0.000 *$ \\
\hline \multirow{3}{*}{$\begin{array}{c}7 \text { Field } \\
\text { MSS- IMRT }\end{array}$} & TPS & $5099.65 \pm 41.54$ & \multirow{3}{*}{0.64} & $0.00 \pm 0.00$ \\
\hline & TLD & $5132.75 \pm 52.95$ & & $12.35 \pm 1.42$ \\
\hline & $\mathbf{p}$ & 0.009 & & $0.000 *$ \\
\hline \multirow{3}{*}{$\begin{array}{c}7 \text { Field } \\
\text { SW- IMRT }\end{array}$} & TPS & $5096.91 \pm 51.76$ & \multirow{3}{*}{0.48} & $0.00 \pm 0.00$ \\
\hline & TLD & $5121.25 \pm 53.88$ & & $12.99 \pm 1.46$ \\
\hline & $\mathbf{p}$ & 0.028 & & $0.000 *$ \\
\hline \multirow{3}{*}{$\begin{array}{c}9 \text { Field } \\
\text { MSS- IMRT }\end{array}$} & TPS & $5083.70 \pm 51.55$ & \multirow{3}{*}{0.84} & $0.00 \pm 0.00$ \\
\hline & TLD & $5126.90 \pm 58.73$ & & $13.18 \pm 1.53$ \\
\hline & $\mathbf{p}$ & $0.003 *$ & & $0.000 *$ \\
\hline \multirow{3}{*}{$\begin{array}{c}9 \text { Field } \\
\text { SW- IMRT }\end{array}$} & TPS & $5090.42 \pm 45.03$ & \multirow{3}{*}{0.73} & $0.00 \pm 0.00$ \\
\hline & TLD & $5127.89 \pm 58.45$ & & $16.10 \pm 2.04$ \\
\hline & $\mathbf{p}$ & 0.011 & & $0.000 *$ \\
\hline
\end{tabular}

*Statistically significant values ( $\mathrm{p}<0.005)$, TPS: Treatment planning system, TLD: Thermoluminescence dosimetry, $\mathrm{D}_{\text {mean }}$ : Mean dose, PTV: Planning target volume, 3D-CRT: Three-dimensional conformal radiotherapy, MSS-IMRT: Multiple static segments-intensity modulated radiotherapy, SW-IMRT: Sliding window- intensity modulated radiotherapy.

\section{DISCUSSION}

The purpose of this study was to estimate the dose received by the fetus in RT of the left breast by using anthropomorphic phantoms simulating the geometry of a pregnant woman in the first trimester of pregnancy. In addition, the accuracy of fetal doses calculated by TPS in left breast RT were compared with TLD measurements. This study will provide the opportunity to choose the right technique in order to obtain the optimum and correct dose distribution in the treatment of a pregnant patient who has to receive left breast RT. According to the generally accepted opinion that is also stated by CRP, there is no need for termination of pregnancy in the case of a fetus exposed to doses less than $10 \mathrm{cGy}$ [4]. In our study, the fetal doses for 3D-CRT and 5 MSS-IMRT treatment techniques in TLD readings were found to be $3.36 \pm 0.19 \mathrm{cGy}$ and $9.32 \pm 0.91 \mathrm{cGy}$, respectively, but in other treatment techniques fetal doses were above $10 \mathrm{cGy}$. Howell et al. [9] investigated the out-of-field dose accuracies for the plan they made for the phantom in Eclipse TPS (v 8.6) using AAA algorithm. They showed that at distances greater than $11.25 \mathrm{~cm}$ from the target volume, the difference between TPS and TLD measurements increased to 55\%. Our study yielded results in parallel with the study conducted by Howell et al. When calculating TPS as 0 cGy for the fetus located at a distance of $25 \mathrm{~cm}$ from the target volume, it was observed that the dose increased according to the technique used in TLD measurements and exceeded $10 \mathrm{cGy}$ in other techniques except 3D-CRT and 5 MSS-IMRT techniques. Mazonakis et al. [10] designed a targeted $6 \mathrm{MV}$ and 50 Gy tangential 3D-CRT treatment plan in their study on the phantom 
and showed that the fetus was exposed to a total dose of 2 to 8 cGy in TLD measurements taken using the phantom. In our study, while the absorbed dose in TPS was calculated as $0 \mathrm{cGy}$ for all treatment techniques, we dosimetrically determined that the doses in TLD readings for 3D-CRT, 5 MSS-IMRT, 5 SW-IMRT, 7 MSS-IMRT, 7 SW-IMRT, 9 MSS-IMRT and 9 SW IMRT techniques were $3.36 \pm 0.19 \mathrm{cGy}, 9.32 \pm$ $0.91 \mathrm{cGy}, 10.29 \pm 1.19 \mathrm{cGy}, 12.35 \pm 1.42 \mathrm{cGy}, 12.99 \pm$ $1.46 \mathrm{cGy}, 13.18 \pm 1.53 \mathrm{cGy}$ and $16.10 \pm 2.04 \mathrm{cGy}$, respectively. Berris et al. [11] calculated the radiation dose of OARs by using the 3D-CRT technique using Monte Carlo simulation model for breast RT and calculated the uterine dose between 1.5 and $3 \mathrm{cGy}$. In our current study, similar to the findings in the study by Berris et al. our mean TLD measurement for the plan made using the 3D-CRT technique and mutual tangential angles was $3.36 \pm 0.19 \mathrm{cGy}$. Van der Giessen et al. [12] stated in their study that as moved away from the target volume, the margin of error may increase and reach up to $33 \%$ in the doses calculated by TPS. In our study, it was seen that calculation error in TPS is much higher for the fetus located $25 \mathrm{~cm}$ from the lower border of PTV. In a study on pregnant patients, in order to reduce the fetal dose delivered during IMRT, Josipovic et al. [13] suggested use of a uterine protective shield, and optimization with as little MU as possible should be preferred for acceptable dose distribution. In our study, the fetal dose for the 3D-CRT technique, which was the lowest MU among all techniques, was $3.36 \pm 0.19$ cGy based on TLD measurement. Wang et al. [13] evaluated the out-offield dose calculated using the TPS (Varian Eclipse v.11 with AAA algorithm) in the treatment plans with the goal of estimating the uncertainties of calculated organ dose. They found that, TPS consistently underestimates out-of-field dose by $30 \sim 50 \%$ of local dose (with jaw tracking turned off) compared with that of Monte Carlo calculations for all beam energies. They indicated these underestimations occur at locations where local doses are less than $1 \%$ of the prescription dose. They suggested that these results are beneficial in providing information on the uncertainties of out-of-field organ doses calculated by TPS. In our study, TLD measurements were found between 3.36 cGy-16.10 cGy in the non-receiving fetus area, which received approximately $1 \%$ of the prescribed dose, while TPS were calculated as $0 \mathrm{~Gy}$.

\section{CONCLUSION}

In conclusion, this study provides analytical data on the fetal exposure dose for 3D-CRT and IMRT treatment techniques of a patient who had to receive left breast radiotherapy during pregnancy. The 3D-CRT is superior to IMRT in terms of fetal protection. If there is concern about the fetal dose during breast RT, 3D-CRT and 5 MSS-IMRT techniques encompassing tangential areas below the 10 cGy threshold can be used. According to the MSS-IMRT technique, the dose to which the fetus is exposed is higher in IMRT plans in which SW-IMRT technique is used. In this respect, the first priority for a pregnant patient who has to undergo left breast RT should be 3D-CRT, but if the desired dose- volume histogram cannot be obtained with 3DCRT, 5 MSS-IMRT technique may be preferred. Since TPS cannot accurately calculate the dose to which the fetus is exposed before starting the treatment, it is recommended to make simulations with Rando phantom and evaluate the dose to which the fetus will be exposed using dosimetric measurements.

Contributions: (I) Conception and design: All authors; (II) Administrative support: Hamit Basaran; (III) Provision of study materials or patients: Osman Vefa Gul; (IV) Collection and assembly of data: Osman Vefa GUL; (V) Data analysis and interpretation: Osman Vefa Gul, Hamit Basaran; (VI) Manuscript writing: Gokcen Inan; (VII) Final approval of manuscript: All authors.

\section{REFERENCES}

[1] Karacam SC, Guralp OS, Oksuz DC, Koca A, Cepni I, Cepni K, Bese N. The investigation of fetal doses in mantle field irradiation. Radiat Prot Dosimetry. 2009;133(3):165-70. doi: $10.1093 / \mathrm{rpd} / \mathrm{ncp} 034$.

[2] W. Phipps, J. D. Harrison, T. P. Fell, K. F. Eckerman, and D. Nosske, "Some aspects of the fetal doses given in ICRP publication 88 . Radiation protection dosimetry," Rad. Protect. Dosimet., vol. 105, pp. 279-284, 2003.

[3] Donegan WL. Cancer and pregnancy. CA Cancer J Clin 1983;33:194e214.

[4] Kourinou KM, Mazonakis M, Lyraraki E, Damilakis J. Photon-beam radiotherapy in pregnant patients: can the fetal dose be limited to 10 cGy or less? Phys Med. 2015;31(1):85-91.

[5] Hartford, A.C., American Society for Therapeutic Radiology and Oncology (ASTRO) and American College of Radiology (ACR) practice guidelines for Intensity-Modulated Radiation Therapy (IMRT), International Journal of Radiation Oncology-Biology-Physics, 73, 1, 914 (2012). 
[6] Chui CS, Chan MF, Yorke E, Spirou S, Ling CC. Delivery of intensity-modulated radiation therapy with a conventional multileaf collimator: Comparison of dynamic and segmental methods. Med Phys 2001;28:2441-9.

[7] Huang JY, Followill DS, Wang XA, SF Kry. Accuracy and sources of error of out-of field dose calculations by a commercial treatment planning system for intensity-modulated radiation therapy treatments. J. Appl. Clin. Med. Phys 14(2):4139; 2013.

[8] Das IJ, Cheng CW, Watts RJ, Ahnesjö A, Gibbons J, Li XA, Lowenstein J, Mitro RK, Simon WE, Zhu TC. Accelerator beam data commissioning equipment and procedures: report of the TG-106 of the Therapy Physics Committee of the AAPM. Med Phys. 2008;35(9):4186-215.

[9] Howell RM, Scarboro SB, Kry SF, Yaldo DZ. Accuracy of out-of-field dose calculations by a commercial treatment planning system. Phys Med Biol. 2010;55(23):6999-7008.

[10] Mazonakis M, Varveris H, Damilakis J, Theoharopoulos N, Gourtsoyiannis N. Radiation dose to conceptus resulting from tangential breast irradiation. Int J Radiat Oncol. 2003;55(2):38691.

[11] Berris T, Mazonakis M, Stratakis J, Tzedakis A, Fasoulaki A, Damilakis J. Calculation of organ doses from breast cancer radiotherapy: A Monte Carlo study. J. Appl. Clin. Med. Phys 14(1):4029; 2013.

[12] Van der Giesen, P. A simple and generally applicable method to estimate the peripheral dose in radiation teletherapy with high energy $\mathrm{x}$-rays or gamma radiation. Int. J. Radiation Oncol. Biol. Phys 35(5):1059-68; 1996.

[13] Josipovic M, Nystrom H, Kjaer-Kristoffersen F. IMRT in a pregnant patient: how to reduce the fetal dose? Med Dosim. 2009;34(4):301-10.

[14] Wang L, Ding GX. Estimating the uncertainty of calculated out-of-field organ dose from a commercial treatment planning system. J Appl Clin Med Phys. 2018 Jul;19(4):319-324. doi: $10.1002 / \mathrm{acm} 2.12367$. 